\title{
Principio de no devolución y su aplicación extraterritorial: pilar fundamental en el marco del derecho de los refugiados ${ }^{1}$
}

\author{
Yara Zulay Riascos Valencia²
}

Envío recibido 2020-07-12 aprobado el 2020-11-17

\section{Cómo citar este artículo:}

Riascos Valencia, Y. Z. (2020). Principio de no devolución y su aplicación extraterritorial: Pilar fundamental en el marco del DERECHO DE LOS REFUGIADOS. Trans-Pasando Fronteras, (16). https://doi.org/10.18046/retf.i16.4167

\footnotetext{
1 Este artículo corresponde a la presentación de un avance del proyecto de investigación denominado "Perspectivas de análisis de los Derechos Económicos, Sociales, y Culturales: dinámicas del desarraigo en Hispanoamérica durante el período 2015-2018" adscrito al Grupo de Investigación Problemas Contemporáneos del Derecho y la Política (GIPCODEP) de la Facultad de Derecho y Ciencias Políticas de la Universidad de San Buenaventura Cali, categorizado en A por Colciencias; siendo realizado en el marco del trabajo investigativo Ilevado a cabo en el semillero Derecho y Poder, del programa de Derecho de la Universidad San Buenaventura de Cali, el cual está dirigido por la docente Stephanie Oliveros Ortiz, profesional en Derecho de la misma universidad.
}

2 Universidad San Buenaventura de Cali-Programa de Derecho Santiago de Cali, Colombia. 


\section{Resumen}

Son varios los principios que cobijan el derecho de los refugiados, pero es el principio de no devolución el que representa fundamentalmente la protección de estas personas, al punto de constituirse como la piedra angular del derecho de los refugiados, según lo dicho por el Alto Comisionado de las Naciones Unidas para los Refugiados (2007). Es tal su importancia, que este principio tiene aplicación extraterritorial, lo cual permite que su cumplimiento no se limite sólo al territorio de los Estados, toda vez que extiende las obligaciones emanadas del principio de no devolución hacia otros territorios en los que tengan un control efectivo sobre los refugiados. En ese sentido, la extraterritorialidad permite que los Estados puedan ser responsables independientemente del lugar en el que haya sido infringido. Así pues, en este artículo se estudiará especialmente las implicaciones de este principio, consagrado (entre otras) en la Convención de 1951 sobre los refugiados y su componente de extraterritorialidad; además, su aplicación se esbozará con criterios jurisprudenciales presentes en algunas sentencias de la Corte Interamericana de Derechos Humanos que han recurrido a tan importante principio en la solución de diversos casos.

Palabras clave: Migrantes, refugiados, Convención de 1951 sobre refugiados, principio de no devolución, aplicación de extraterritorialidad. 


\title{
Principle of non-refoulement and its extraterritorial application: fundamental pillar within the framework of refugee law
}

\begin{abstract}
There are several principles that protect refugee law, but it is the principle of non-refoulement that fundamentally represents the protection of these people, that to the point of becoming the "cornerstone of refugee law", as stated by the United Nations High Commissioner for Refugees (2007). Its importance is such that this principle has extraterritorial application, which allows its compliance not to be limited only to the territory of the States, since it extends the obligations emanating from the principle of non-refoulement to other territories in which it exercises effective control over refugees. In this sense, extraterritoriality allows for States to be held accountable regardless of the place where it has been infringed. Thus, this article will especially study the implications of this principle, enshrined (among others) in the 1951 Convention on Refugees, and its extraterritoriality component; in addition, its application will be outlined with jurisprudential criteria present in some decisions from the Inter-American Court of Human Rights, who has repeatedly mentioned this principle in the solution of various cases.
\end{abstract}

Keywords: Migrants, refugees, 1951 Refugee Convention, principle of non-return, application of extraterritoriality. 
"Nada ha ganado el perseguido con abandonar el país donde su vida o libertad están amenazadas, si no está protegido contra la devolución. Sin este principio, el refugiado mantendrá sus fundados temores en todos los rincones de la tierra"

Garretón, 1995.

\section{Introducción:}

A través de los tiempos han sido miles las personas que han decidido empezar una nueva vida en un Estado diferente al de su nacionalidad o residencia habitual, por diversas razones bien sea sociales, económicas, políticas, etc. A su vez, con el fin de garantizar la protección de los derechos humanos, la comunidad internacional ha ido desarrollando diversos mecanismos o acuerdos que reconocen los derechos de la población migrante desde diferentes ámbitos como el laboral, el de acceso a la justicia, incluso el derecho a la libertad de circulación y de residencia. En ese orden de ideas, también se desarrolló la figura del Refugiado de la siguiente manera:

- Convención de 1951 sobre los refugiados: es un instrumento internacional en el que se determinó la institución del refugiado y se estableció una serie de derechos en torno a la misma, con el objetivo principal de brindar protección internacional a las víctimas tras la Segunda Guerra mundial, estableciendo en parte del artículo primero, ciertas limitaciones geográficas y temporales, es decir, un ámbito de aplicación restringido básicamente al europeo y su aplicación a acontecimientos ocurridos antes de 1951.

- Protocolo de 1967: El Alto Comisionado de las Naciones Unidas para los Refugiados (2007), indica que en este protocolo se eliminaron 
Las limitaciones geográficas y temporales contenidas en la Convención original, según las cuales, en la mayoría de los casos, sólo los europeos involucrados en los hechos acaecidos antes del 1 de enero de 1951 podían solicitar asilo. Como resultado, convirtió a la Convención en un instrumento verdaderamente universal que podría beneficiar a los refugiados en cualquier lugar.

En otras palabras, el objetivo de la creación del Protocolo de 1967 fue ampliar el ámbito de la definición de quienes podrían ser reconocidos como refugiados y acceder por lo tanto a la protección internacional, de tal manera que estos no se ciñeran sólo a lo estipulado en la Convención de 1951. Así pues, los Estados parte en dicho protocolo consideraron la necesidad de dar importancia a nuevas situaciones que requieren de la protección propia de un refugiado. (Rubio, 1999; Alto Comisionado de las Naciones Unidas para los Refugiados, 2011). Conforme a lo anterior, en el numeral 2 del artículo 1 del protocolo, se omitieron ciertas palabras contenidas en la definición de refugiado de la mencionada Convención, de la siguiente manera:

2. A los efectos del presente Protocolo y salvo en lo que respecta a la aplicación del párrafo 3 de este artículo, el término "refugiado" denotará toda persona comprendida en la definición del artículo 1 de la Convención, en la que se darán por omitidas las palabras "como resultado de acontecimientos ocurridos antes del 1. ' de enero de 1951 y..." y las palabras "... a consecuencia de tales acontecimientos", que figuran en el párrafo 2 de la sección A del artículo 1.

Declaración de Cartagena sobre los Refugiados de 1984: en este instrumento, se amplía conceptualmente la definición de refugiado, incorporando también a aquellas personas, que entre otros factores, se fueron de sus países a causa de la violencia generalizada. Así pues, se estableció en el apartado III, conclusión Tercera de la Declaración, que es recomendable que la definición de refugiado, además de contener lo establecido en la Convención de 1951 y el Protocolo de 1967, considere también como refugiados a : 
Las personas que han huido de sus países porque su vida, seguridad o libertad han sido amenazadas por la violencia generalizada, la agresión extranjera, los conflictos internos, la violación masiva de los derechos humanos u otras circunstancias que hayan perturbado gravemente el orden público.

Dicho lo anterior, se han establecido una serie de derechos y garantías que conforman lo que ha sido denominado como el derecho de los refugiados, en donde encontramos un principio muy importante, sobre el que trata este trabajo investigativo, como lo es el principio de no devolución, el cual se originó como una necesidad de brindar cierta seguridad para todas aquellas personas que se han visto obligadas a salir de su país de origen o residencia habitual por motivo de persecución, con el fin de buscar seguridad para sus vidas en otros Estados, y que en virtud de este principio, tengan una garantía que les permita arribar a un determinado territorio, sin el temor de ser devueltos, siempre y cuando reúnan los presupuestos estipulados para ser considerado refugiado.

\section{Estrategias metodológicas:}

Este trabajo investigativo es de tipo descriptivo, ya que su objeto es precisamente la caracterización del principio de no devolución, a partir de sus elementos cualitativos; ello mediante un proceso de investigación y análisis documental.

Además, esta investigación también contiene un análisis jurisprudencial, donde se analizarán ciertas sentencias que hacen referencia a la aplicación del principio de no devolución dictadas por la Corte Interamericana de Derecho Humanos, para reconocer las novedades y ratio decidendi establecidas en cada una de ellas.

\section{Objetivos:}

\section{Objetivos generales:}


- Comprender el concepto y alcance del Principio de no devolución en el marco de los estándares internacionales de derechos humanos dentro del contexto del Sistema Interamericano de Derechos Humanos.

\section{Objetivos específicos:}

- Analizar el concepto del principio de No Devolución y sus características en el marco jurídico internacional de los derechos humanos.

- Analizar la aplicación de extraterritorialidad contenida en el principio de no devolución y sus implicaciones para los Estados en el marco jurídico internacional.

- Observar los criterios jurisprudenciales planteados por la Corte IDH referente al principio de No Devolución.

Ahora, antes de pasar al análisis conceptual del principio de no devolución, es necesario abordar la definición de algunos términos que tienen gran relevancia para efectos de comprender el tema:

- Migrante: persona que se traslada de su Estado de nacimiento o de ciudadanía hacia el territorio de otro Estado; León Amparo (2005) citando a Tizón, menciona que la migración que le da la calificación a las personas como migrantes es:

Aquella en la cual el traslado se realiza de un país a otro, o de una región a otra la suficientemente distinta y distante, por un tiempo suficientemente prolongado como para que implique vivir en otro país, y desarrollar en él las actividades de la vida cotidiana.

Partiendo de las diversas razones por las que una persona puede migrar de un Estado a otro, bien sea de forma voluntaria o de manera forzosa, la migración se puede considerar en un sentido amplio, en el que se incluye a los refugiados, perteneciendo al tipo de migración forzosa, ya que se ven obligados a irse hacia otro Estado para garantizar su vida y seguridad, ya que se vería afectada en el caso de quedarse en su 
país de residencia habitual, por lo cual estos cumplen con unas causas especiales y reciben la protección del Estado asilante; aspectos estos que pasaremos a observar en la siguiente definición.

Dicho lo anterior, es menester indicar que debemos ser precisos al momento de catalogar a una persona como migrante o refugiada, pues no es lo mismo hablar de quien ha migrado voluntariamente a quién se ha movilizado de un Estado a otro por situaciones apremiantes de integridad y seguridad y que requiere de asistencia por la misma situación; entonces, referirnos simplemente como "migrante" a una persona que ostenta la calidad de refugiado, nos conduce a un error sustancial basándonos en la protección que tienen las personas propiamente refugiadas; por ello, para evitar caer en imprecisiones es mejor recurrir al término de refugiado cuando sea el caso.

Refugiado: conforme a los términos del artículo 1 de la Convención sobre el Estatuto de los Refugiados de 1951, el Protocolo de 1967 y la Declaración de Cartagena sobre los Refugiados de 1984, Garretón define a un refugiado como aquella persona que:
(...) se encuentra fuera de su país, careciendo de la protección de este, en razón de (sic) fundados te- mores de ser perseguida por motivos de raza, religión, nacionalidad, pertenencia a determinado grupo so- cial u opciones políticas, o de encontrarse amenaza- da por la violencia generalizada, la agresión extran- jera, los conflictos internos, la violación masiva de los derechos humanos u otras circunstancias que hayan perturbado gravemente el orden público. (Garretón, 1995, p. 213).

Así pues, un refugiado es toda persona que se encuentra bajo las causales mencionadas en el párrafo anterior, por lo cual, un individuo puede ser un refugiado incluso cuando un Estado no lo haya reconocido como tal, lo cual indica que la calidad de refugiado la ostentan per se todos aquellos que se encuentren bajo las condiciones de peligrosidad 
establecidas en la Convención de refugiados y en la Convención Americana de Derechos Humanos. En ese orden de ideas, el acto por el que un Estado reconoce el status de refugiado de una persona es declarativo, más no constitutivo, puesto que materialmente ya lo era sin el pronunciamiento del Estado asilante.

Así las cosas, es necesario mencionar lo dicho por el ACNUR al respecto:
(...) una persona no se convierte en refugiada porque se le reconoce como tal, sino que se le reconoce porque es refugiada. En consecuencia, el principio de no devolución se aplica no sólo a los refugiados reconocidos, sino que también a aquellos a quienes no se les ha declarado formal- mente su estatuto. (ACNUR, 2007, p. 3).

Por otro lado, el reconocimiento del derecho de los refugiados permite garantizar, además de la no devolución al Estado en que la persona corre peligro, la protección y el amparo del Estado asilante, es decir, el refugiado recibe asistencia de diversa índole que le permita llevar a cabo una vida en la que por lo menos se satisfagan sus necesidades elementales y se procure por una solución eficiente a su situación; dicho amparo emana no sólo del auxilio del Estado asilante, sino también de la acción del Alto Comisionado de las Naciones Unidas para los Refugiados (ACNUR), organización mundial que se encarga entre otras cosas de planear y llevar a cabo programas que permitan brindar herramientas y la asistencia necesaria a los refugiados como alimentos, agua potable, albergues, escolarización, etc., para que estos puedan convivir en condiciones dignas y bajo la observancia de sus derechos humanos, lo cual logran en gran parte, mediante el aprovechamiento de las donaciones hechas por Estados, entidades privadas y Organizaciones No Gubernamentales (ONG) para tal fin.

-Asilo político: es la protección que un Estado, Ilamado asilante, concedeaaquellaspersonasquehanhuidodesupaís pormotivos políticos. 
Envirtud de esta institución, el Estado asilante se compromete a brindar una protección efectiva al asilado, adquiriendo así una obligación.

-Asilo humanitario: es un término que concibe una concepción más amplia del asilo, en donde se contemplan las mismas causales del refugio.

-Asilo: En congruencia con la definición anterior, este es un término que abarca toda la protección que un país brinda a los refugiados en su territorio; constituyendo entonces el derecho que tiene toda persona de buscar asilo. De tal manera, una persona a la cual se le otorga el asilo, se convierte en refugiado. ACNUR (2001).

- Solicitante de asilo: el ACNUR (2001) indica que este término puede referirse a la persona que ha presentado una solicitud de asilo con el fin de que le sea reconocido su status de refugiado, encontrándose a la espera de una decisión; o también se refiere a aquella persona que aún no ha presentado su respectiva solicitud.

-Expulsión: es el evacuar a una persona del territorio de un Estado, lo cual está prohibido salvo que se haga en virtud de garantizar el orden público y la seguridad nacional, claro está, una vez realizado el análisis respectivo del caso y que la decisión haya sido adoptada conforme a un debido proceso, teniendo presente, que las expulsiones colectivas están prohibidas cuando no se ha hecho el estudio individual de cada caso, tal como está estipulado en el numeral 9 del artículo 22 de la Convención Americana sobre Derechos Humanos. En otras palabras, y según lo dicho por el ACNUR (2001), la expulsión es el desalojo de una persona que reside legalmente en el territorio de un Estado, por las autoridades públicas.

-Devolución: consiste en devolver a una persona al Estado del que salió por encontrarse su vida en peligro. La devolución como veremos más adelante, se encuentra prohibida cuando se lleva a cabo sin el estudio previo del caso, que permita descartar el peligro manifestado 
por el refugiado. Conforme a lo establecido por el ACNUR (2001), la devolución es

La circunstancia en que una persona es devuelta a las fronteras de un territorio donde puede ser perseguida o trasladada a otro territorio en el que corre el riesgo de ser perseguida. Este acto constituye una violación del principio de no devolución y, por ende, es una infracción del derecho de los refugiados y del derecho internacional consuetudinario.

Así pues, tratándose de la devolución, las personas no se encuentran legalmente en el Estado del que son devueltas, a diferencia de la expulsión, en la que el refugiado sí se halla legalmente en el territorio.

-Extradición: es el proceso por el que un Estado entrega formalmente un individuo sospechoso o condenado a otro Estado que tiene jurisdicción sobre la persona. En otras palabras y según lo dicho por el ACNUR (2008), la extradición es un proceso formal en el que un Estado requirente solicita a un Estado, Ilamado requerido, la entrega de una persona ante sus autoridades, con el propósito de ser procesada penalmente o para ejecutar una sentencia penal.

El Comité Ejecutivo mediante la Conclusión No. 17 (XXXI) DE 1980, expuso que se debía proteger a los refugiados con respecto a la extradición a un país donde tuviesen fundados temores de ser perseguidos, haciendo referencia a aquellos que cumplen con la condición de refugiado conforme a lo estipulado en la Convención sobre el Estatuto de los refugiados de 1951 y que estén excluidos de los estipulado en el apartado b, sección F, del artículo 1 de la mencionada convención, es decir que no hayan cometido un grave delito común, fuera del país de refugio, antes de ser admitida en él como refugiado. Claro está que el país al cual se va a expulsar a la persona, debe asegurar mediante garantías diplomáticas que el individuo no correrá riesgo alguno de ser perseguido o sometido a tratos crueles. 
-Deportación: acto mediante el cual un Estado envía a un extranjero fuera de su territorio, generalmente hacia su país de origen o residencia habitual, cuando haya rechazado su respectiva solicitud de asilo (Revista Migraciones Forzadas, 2017).

\section{Comienzos del principio de no devolución:}

Según Garretón (1995), el principio de no devolución comenzó a tener aplicación a mediados del siglo XIX, al negarse la extradición de delincuentes políticos. Sin embargo, este empezó a ser desarrollado con mayor amplitud en Europa, en el periodo entre la Primera y Segunda Guerra mundial, ya que se empezaron a expedir varios acuerdos entre Estados que establecían derechos frente a los refugiados alemanes y rusos, y prohibían la expulsión de los mismos hacia Alemania. Ejemplos de ello, fueron:

En el artículo 3 de la Convención Relativa a la Condición Jurídica Internacional de los Refugiados de 1933, los Estados se comprometieron a no aplicar medidas policiales tales como expulsiones o no admisión en la frontera.

Más tarde, el Acuerdo de 1936 disponía que "Ios refugiados no deberán ser devueltos a la frontera del Reich" y la Convención de 1938 dispuso que los Estados Partes se comprometieran a no reconducir a los refugiados a territorio alemán. (Garretón, 1995, p. 215).

Desde dicha época, son varias las convenciones que se han suscrito estableciendo medidas de protección para los refugiados, con las cuales adquirió sentido el hecho de que una persona se traslade de un Estado a otro, en virtud de las razones establecidas en la Convención de 1951, puesto que sería absurdo que se permitiera la devolución de los refugiados a un Estado en el que su vida e integridad corre peligro y que no cuente con la protección del mismo; y es que como bien dice Roberto Garretón (1995, p. 2), "nada ha ganado el perseguido con abandonar el país donde su vida o libertad están amenazadas, si no está protegido contra la devolución. Sin este principio, el refugiado mantendrá sus fundados temores en todos los rincones de la tierra". 
Ahora bien, son varias las convenciones que contemplan el principio de no devolución, como lo es la Convención Sobre el Estatuto de los Refugiados de 1951, siendo esta es la más representativa en torno al tema de los refugiados, la cual pasaremos a citar seguidamente.

\section{Concepto del principio de no devolución:}

La Convención Sobre el Estatuto de los Refugiados de 1951, establece el principio de no devolución o non refoulement en el numeral 1 del artículo 33; en este se dispone lo siguiente:

1. Ningún Estado Contratante podrá, por expulsión o devolución, poner en modo alguno a un refugiado en las fronteras de los territorios donde su vida o su libertad peligre por causa de su raza, religión, nacionalidad, pertenencia a determinado grupo social, o de sus opiniones políticas.

Igualmente, la Convención Americana de Derechos Humanos establece dicho principio en el numeral 8, del artículo 22, de la siguiente manera:

8. En ningún caso el extranjero puede ser expulsado o devuelto a otro país, sea o no de origen, donde su derecho a la vida o a la libertad personal está en riesgo de violación a causa de raza, nacionalidad, religión, condición social o de sus opiniones políticas.

Así pues, el principio de no devolución prohíbe a los Estados receptores de los refugiados, la devolución de estos al Estado donde su vida corre peligro debido a determinada situación, pues tal como lo menciona la ACNUR,

(...) antes de aplicar cualquier medida de deportación, los Estados tienen el deber de establecer que la persona a quien pretenden $\quad d e$ portar de su territorio o jurisdicción no quedará expuesta al peligro de graves violaciones a sus derechos humanos (...). De existir tal peligro, el Estado debe descartar la expulsión forzosa de la persona en cuestión. (ACNUR, 2007, p.13) 
Este principio además de ser considerado la piedra angular de la protección de los refugiados, se constituye como un principio propio del ius cogens y del derecho internacional consuetudinario. Es decir, es un principio de amplia aceptación y práctica internacional,y por ende es de obligatorio cumplimiento tanto por los Estados que son parte como por los que no lo son, en los instrumentos que lo consagran, como la Convención de 1951, el Protocolo de 1967 y la Convención contra la tortura.

Es tan importante este principio, que siendo considerado el derecho de asilo como un derecho fundamental de los seres humanos, la no devolución constituye la garantía a este derecho. Además, según lo mencionado por Garretón (1995), siendo el principio de no devolución, un principio ius cogens, constituye incluso por sí solo un derecho humano.

Conforme a lo anterior, podemos decir que las características del principio de no devolución son las siguientes:

- Limita el poder de los Estados sobre su territorio.

- Es una norma del derecho internacional consuetudinario.

- Es de carácter relativo.

- Es oponible a todos los refugiados, aunque aún no les haya sido reconocido el estatus de refugiado o asilado.

Como se mencionó anteriormente, este principio es de carácter relativo, lo cual quiere decir que los Estados no tienen siempre la obligación absoluta de aplicarlo, ya que existen ciertas causales establecidas en el artículo 33.2 de la Convención Sobre el Estatuto de los Refugiados de 1951, por las que excepcionalmente una persona no podría ser beneficiada con este principio. Dichas causales son las siguientes: 
- Que, por razones fundadas, la persona sea considerada un peligro para la seguridad del país: al respecto, el ACNUR (2008) manifiesta que la persona debe ser considerada un peligro o amenaza presente o futura, muy grave para la seguridad del país.

- Que la persona habiendo sido objeto de una condena definitiva por un delito particularmente grave, constituya una amenaza parala comunidad del país: respecto de esta causal, es menester mencionar que la comisión de un delito "particularmente grave", no se refiere como bien lo menciona Garretón (1995), a la gravedad de la pena, sino que ello depende de que el delito como tal, sea considerado de tal magnitud al reunir ciertas condiciones que pueden ser dadas por ejemplo en instrumentos internacionales, como delitos relativos a la violación de derechos humanos, siendo uno de ellos, el de tortura, el cual se encuentra catalogado como particularmente grave por la Convención contra la Tortura y otros tratos o penas crueles, inhumanos y degradantes.

En este punto, es importante resaltar que el hecho de que una persona sea condenada por un delito particularmente grave, no quiere decir que también represente una amenaza para la comunidad del país, sino que se debe estudiar el caso para llegar a tomar esa determinación. El ACNUR (2008) expone que para establecer si la persona que cometió el delito particularmente grave constituye igualmente una amenaza para la comunidad, es menester hacer algunas consideraciones relativas a la naturaleza del delito cometido y de ciertas circunstancias como por ejemplo la reincidencia.

Si bien las anteriores representan excepciones a la aplicación del principio de no devolución, estas no pueden ser consideradas como justificaciones para evadir su cumplimiento, toda vez que un Estado sólo debe adoptar el non-refoulement cuando no existan otras medidas menos severas, de tal manera que la devolución tiene una aplicación meramente restrictiva. Dicho lo anterior, cuando un Estado 
decida devolver a una persona, debe demostrar que el daño que se le podría ocasionar a la persona en cuestión al devolverla es menos grave que el riesgo de daño que le podría generar esta al Estado si lo dejan en el territorio.

Así pues, dichas causales son taxativas, por ello los Estados deben justificar adecuadamente el motivo que tengan para devolver a una persona al territorio del que decidieron salir, porque de lo contrario estarían vulnerando un principio que a su vez constituye un derecho de los refugiados. De tal manera, es necesario mencionar que los obligados a cumplir con este principio son tanto el Estado, como todas aquellas entidades o personas que actúen en su nombre.

Otro aspecto fundamental del principio de no devolución es que este aplica para todos los refugiados, independientemente de su estatus como tal, pues como lo mencionamos anteriormente, el reconocimiento como refugiado es simplemente declarativo y no constitutivo.

\section{Imagen 1. Definición del Principio de no devolución.}

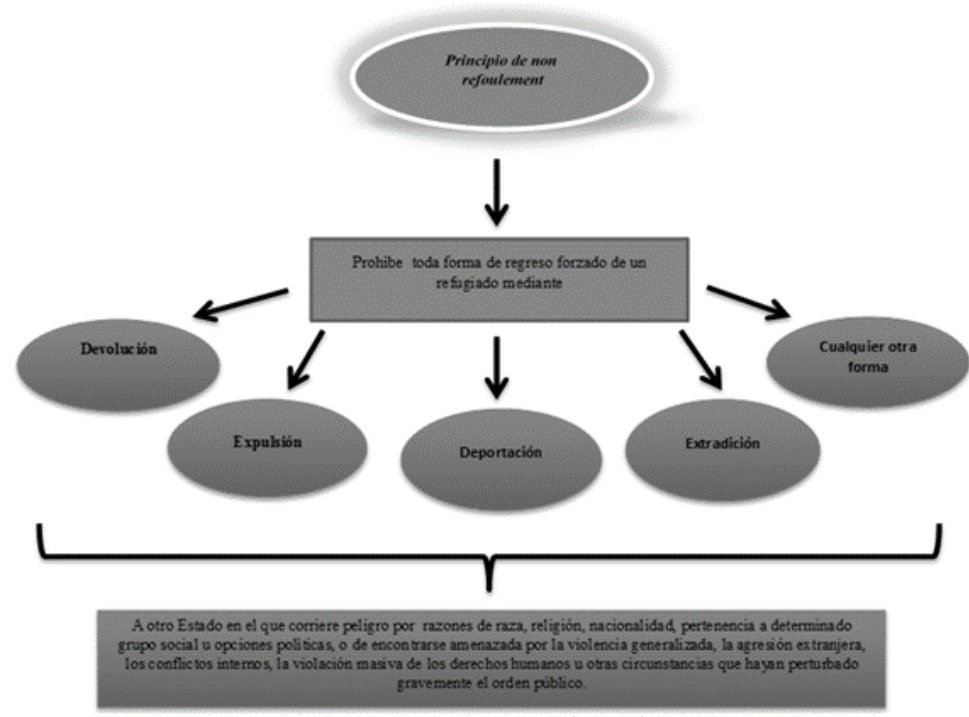


Ahora pasaremos a analizar con mayor profundidad la aplicación extraterritorial del principio de no devolución, la cual es una de las características más significativas.

\section{Aplicación extraterritorial del principio de no devolución:}

El principio de no devolución contiene un interesante componente de extraterritorialidad, según el cual un Estado no puede devolver a un refugiado al territorio en el que este tiene fundados temores de ser perseguido, ni desde su propio territorio, ni desde un lugar en que no ejerza soberanía. Esto sin importar si se trata de altamar, fronteras o de cualquier otro espacio geográfico distinto al suyo.

Lo anterior debido a que el factor determinante no es el territorio como tal, sino el control efectivo del Estado, bajo el que se pudiere encontrar la persona, esto quiere decir que, en razón de la materia, una persona puede estar bajo la jurisdicción de un Estado independientemente del territorio en que se encuentre.

Así pues, la aplicación extraterritorial es la responsabilidad que recae sobre un Estado cuando, bien sea por acción u omisión, perpetra una violación a tan importante principio, en un territorio ajeno al propio del Estado. Es decir que, sin importar que la persona se encuentre en otro país distinto al Estado en cuestión, el hecho de que por medio de sus agentes o con la aquiescencia del gobierno de dicho territorio, se atente contra la persona, lo hace responsable. Siendo así, la prohibición establecida en el artículo 33.1 de la Convención de 1951, no se puede limitar geográficamente al territorio de un Estado al cual arribó un refugiado, de tal manera que el principio de no devolución no tiene restricciones geográficas.

En virtud de lo anterior, cuando de la obligación del principio de non refoulement se trate, no hay lugar a limitar su alcance ratione loci frente al territorio del Estado, ya que desdibuja la verdadera esencia del derecho de los refugiados, que versa sobre la real protección y salvaguarda de 
sus derechos humanos, especialmente de su vida e integridad. Por lo tanto, la observancia o criterio decisivo se ciñe a la efectiva autoridad y control del Estado sobre la persona, refiriéndonos entonces a su especial alcance ratione materiae, es decir, la no devolución a un Estado en el que corriere peligro la vida e integridad del refugiado por motivos de raza, religión, nacionalidad, pertenencia a determinado grupo social u opciones políticas, violencia generalizada, agresión extranjera, conflictos internos, violación masiva de los derechos humanos u otras circunstancias que perturben gravemente el orden público. Además, es menester resaltar que está prohibida la devolución no sólo hacia el Estado de peligro para la persona, sino también hacia un territorio desde el cual pueda ser enviada subsecuentemente a dicho Estado.

Conforme a lo anterior, el ACNUR ha mencionado que:

Así, una interpretación que restringiera el alcance de la aplicación del artículo 33 (1) de la Convención de 1951 a la conducta dentro del territorio de un Estado parte de la Convención de 1951 y/o su Protocolo de 1967, no sólo sería contraria a los términos de la disposición sino al objeto y fin del tratado bajo interpretación. Asimismo, sería incongruente con las normas pertinentes del derecho internacional de los derechos humanos. La posición del ACNUR, por tanto, es que el Estado se encuentra compelido por su obligación en virtud del artículo 33 (1) de la Convención de 1951 a no devolver a los refugiados al peligro de persecución donde quiera que ejerza efectiva jurisdicción. (ACNUR, 2007, p.22).

Enconsecuencia, es evidente la lógica que tiene la extraterritorialidad en materia de no devolución, ya que de no tener aplicación, sería fácil hacernos la idea de que un Estado se dedicara a expulsar o devolver refugiados sin importarle siquiera cual podría ser el destino que correría. Por esa razón, el ACNUR ha manifestado lo siguiente:

Al determinar si están en discusión las obligaciones de derechos humanos de un Estado con respecto a una determinada persona, el criterio decisivo no es si la persona se encuentra en el territorio 
nacional del Estado o en un territorio que está de jure bajo el control soberano del Estado. Más bien, si esa persona está sujeta o no a la efectiva autoridad y control del Estado. (ACNUR, 2007, p.19).

\section{Imagen 2. Definición de la aplicación de extraterritorialidad.}
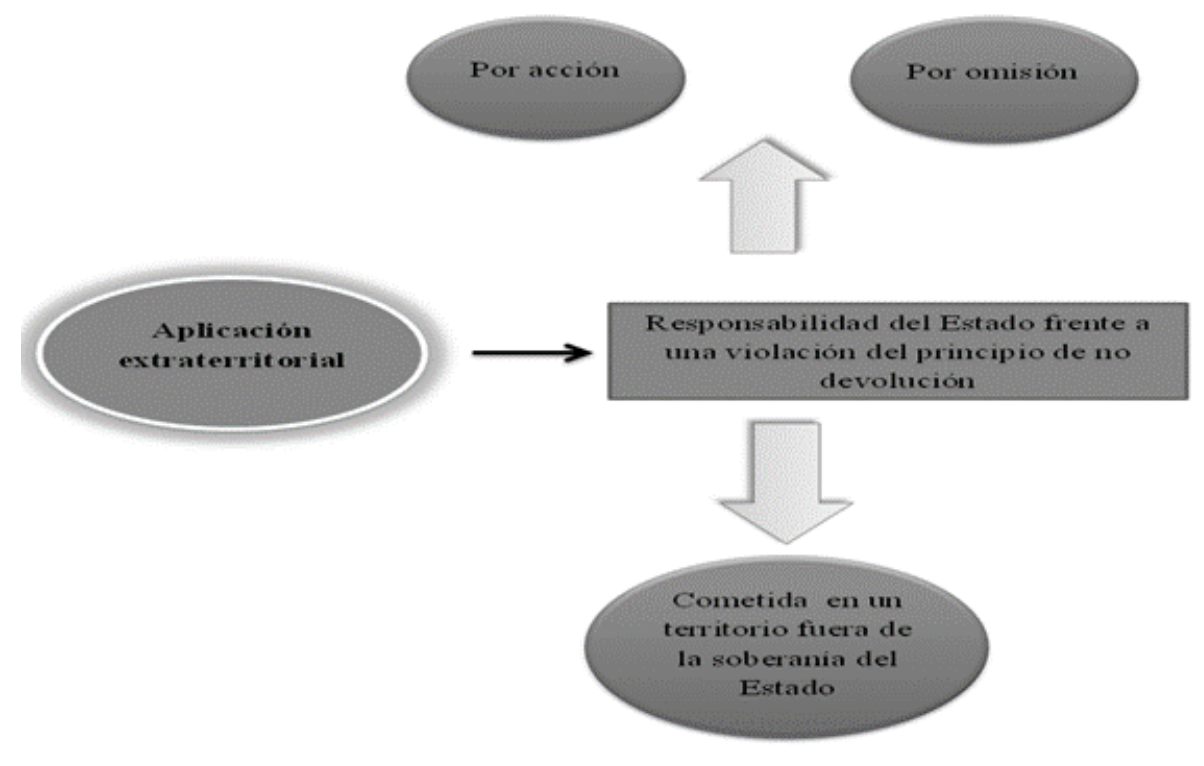

Fuente: Elaboración propia

Así pues, el limitar la aplicación del principio de no devolución a un territorio geográfico determinado, es inadmisible e incluso considerado como una amenaza directa a este principio, toda vez que los Estados bajo esa falsa interpretación pueden consumar violaciones contra este principio para impedir de forma anticipada el arribo de refugiados a su territorio, lo cual es manifestado por el Alto Comisionado de las Naciones Unidas, en los siguientes términos:

Otra amenaza a la aplicación universal del principio de no devolución ha sido la alegación de los Estados de que ese principio no es obligatorio fuera de su propio territorio nacional, de manera que un gobierno 
puede devolver directamente a los refugiados a lugares en que pueden ser perseguidos siempre que no hayan llegado todavía a su frontera ni hayan entrado en su territorio. Esta alegación es claramente incompatible con el propósito de la Convención de 1951 y su Protocolo de 1967, contraria a su espíritu y, en general al del derecho internacional de los refugiados. (ACNUR, 1993, p.6)

Por otro lado, el principio de no devolución y su concepto de extraterritorialidad, no buscan que un Estado se vea obligado definitivamente a aceptar el ingreso y la permanencia de un migrante en su territorio, lo que busca es que se den a la tarea de ofrecerle ciertas condiciones de seguridad, mientras se resuelve su situación, independientemente de si estas ingresaron de forma regular o irregular, pues los Estados tienen la obligación de llevar a cabo el proceso que sea necesario para investigar la situación de la persona y realizar el acompañamiento pertinente para resolver su estadía y salvaguardar sus derechos, siempre y cuando se den los supuestos establecidos en la Convención de 1951 y el Protocolo de 1967.

Lo anterior, nos permite observar que no se trata de que los Estados adopten una actitud de abstención, sino que desplieguen medidas positivas efectivas para la protección del migrante.

\section{Aplicación del principio de no devolución:}

Son diversas las sentencias judiciales que permiten observar el reconocimiento de estos principios en el ámbito internacional. A continuación, se presentarán algunas sentencias emitidas por la Corte Interamericana de Derechos Humanos, con las que haremos énfasis en las subreglas o desarrollo jurisprudencial generado por dicha Corte frente al manejo del principio de no devolución

\section{Caso familia pacheco tineo vs. estado plurinacional de bolivia:}

Esta sentencia del 25 de noviembre de 2013, versa sobre la Familia Pacheco Tineo, oriunda de Perú, compuesta por Rumaldo 
Juan Pacheco Osco, su esposa Fredesvinda Tineo Godos y sus hijos Juana Guadalupe, Frida Edith y Juan Ricardo Pacheco Tineo, este último originario de Chile; Ios cuales partieron hacia la República de Bolivia.

La Corte Interamericana de Derechos Humanos, recalca en esta sentencia el deber que tienen los Estados de examinar la situación de cada refugiado antes de tomar la decisión de expulsarlas o deportarlas de su territorio, ello sin ningún tipo de discriminación por factores como nacionalidad, raza, sexo, lengua, religión, opinión política, etc. Además, manifiesta que se deben adoptar las siguientes garantías mínimas:

i) ser informado expresa y formalmente de los cargos en su contra, si los hubiere, y de los motivos de la expulsión o deportación. Esta notificación debe incluir información sobre sus derechos, tales como:

a. la posibilidad de exponer las razones que lo asistan en contra de su expulsión y oponerse a los cargos en su contra;

b. la posibilidad de solicitar y recibir asesoría legal, incluso a través de servicio público gratuito de ser aplicable y, de ser el caso, traducción o interpretación, así como asistencia consular, si correspondiere;

ii) en caso de decisión desfavorable, debe tener derecho a someter su caso a revisión ante la autoridad competente, presentarse o hacerse representar ante ella para tal fin, y

iii) la eventual expulsión solo podrá efectuarse tras una decisión fundamentada conforme a la ley y debidamente notificada. (Corte IDH, 2013, p. 45)

En esta reconocida sentencia, la Corte IDH, reitera que los Estados receptores siempre deben hacer el debido acompañamiento a las personas, y abordar su caso mediante diversos mecanismos como una entrevista mediante la cual puedan obtener información directa y necesaria, para someterla a prueba; todo con las debidas garantías mínimas y mediante el procedimiento respectivo. 
La Corte IDH declaró al Estado Plurinacional de Bolivia responsable por la violación del principio de no devolución contenido en el Derecho de circulación y residencia, establecido en la Convención Americana de Derechos Humanos. Dicha decisión fue tomada porque si bien un Estado no está en la obligación de otorgar asilo a una persona, sí está en la obligación de llevar a cabo el proceso pertinente que le permita llegar a la decisión de otorgarlo o no. Según las consideraciones de la Corte, la forma en que fue expulsada la familia Pacheco Tineo del Estado de Bolivia a la República del Perú, fue incompatible con lo estipulado en la Convención, toda vez que no se efectuó ninguna valoración sobre el riesgo potencial que podían enfrentar en ese país, más aun teniendo conocimiento de que el niño Juan Pacheco Tineo, era de nacionalidad chilena; en donde incluso tenían el estatus de refugiados. Así pues, Bolivia además de tomar la decisión de expulsarlos, no les informó de ello, negándoles la oportunidad de conocer los fundamentos de ésta y de impugnar la respectiva resolución.

Todo lo anterior constituye claramente una violación al derecho de acceso a las garantías mínimas y al debido proceso contenidos en la $\mathrm{CADH}$ y consecuentemente al principio de no devolución.

\section{Caso nadege dorzema y otros vs. república dominicana:}

En esta sentencia del 24 de octubre de 2012, se expone el caso de un grupo de haitianos que ingresaron al Estado de República Dominicana, los cuales recibieron malos tratos por parte las fuerzas militares de este país, causándoles heridas e incluso ocasionando la muerte de siete personas. La Corte IDH, en sus consideraciones, pone de manifiesto la prohibición que tienen los Estados de expulsar migrantes de forma colectiva, la cual está consagrada en el numeral 9, artículo 22, del derecho de circulación y residencia de la Convención Americana sobre derechos humanos, además de recordar el deber de respeto y garantía de los derechos de los migrantes que tienen los Estados receptores, teniendo en cuenta que en este caso se violaron diversos derechos como 
el de la integridad, la vida y el derecho de circulación y residencia, contenidos en la Convención mencionada.

La Corte expone en dicha sentencia que el carácter "colectivo" de una expulsión implica una decisión que no desarrolla un análisis objetivo de las circunstancias individuales de cada extranjero, y por ende recae en arbitrariedad" (Corte IDH, 2012, p.49). Además, se pone en evidencia, la estrecha relación que tiene el principio de no devolución con derechos como el de las garantías judiciales y la protección judicial, puesto que República Dominicana, expulsó a este grupo de personas sin sujeción alguna a las garantías que tienen en su calidad de migrantes. En ese sentido, la Corte IDH mencionó que "el Estado trató a los migrantes como un grupo, sin individualizarlos o darles un trato diferenciado como ser humano y tomando en consideración sus eventuales necesidades de protección" (Corte IDH, 2012, p. 51).

El Tribunal Europeo de Derechos Humanos (1999) citado en esta sentencia por la Corte IDH (2012, p.49), menciona en relación con la expulsión colectiva de extranjeros que cualquier decisión tomada por autoridad competente que obligue a los extranjeros como grupo a abandonar el país, recae en arbitrariedad, excepto cuando tal medida sea tomada luego de o en base a un examen razonable y objetivo de los casos particulares de cada extranjero.

Así pues, la República Dominica, además de ser declarada por la Corte IDH, como responsable por la violación de diversos derechos y del deber de no discriminación, consagrado en el 1.1 de la Convención Americana de Derechos Humanos, fue declarada responsable dela violación de la prohibición establecida en el 22.9 de la misma, referente a la expulsión colectiva de extranjeros, lo cual a su vez constituye el desconocimiento al principio de no devolución. 


\section{Caso wong ho wing vs. perú:}

Esta sentencia del 30 de junio de 2015, emitida por la Corte Interamericana de Derechos Humanos, versa sobre el caso del señor Wong sentencias como la pena de muerte o tratos crueles, inhumanos o degradantes, siendo esto necesario para dar aplicación primordial al principio de no devolución.

Aquellos riesgos pueden ser analizados con base en un estudio de diversos factores como la existencia de garantías diplomáticas, de las cuales hizo uso el Tribunal como uno de los elementos para la adopción de la decisión. Dichas garantías son necesarias ya que constituyen mecanismos utilizados entre los Estados para garantizar un correcto proceder en temas de extradición, de tal manera que se permita inferir de las mismas que el Estado requirente porta un compromiso de hacer uso del debido proceso y que va a prescindir de tratos que atenten contra lo estipulado en materia de derecho de los refugiados. Consecuentemente, el Estado requerido estaría adoptando las medidas necesarias antes de tomar la decisión de dar en extradición a la persona, para no infringir el principio de no devolución, dejando claramente establecido que la vida del refugiado no va a correr peligro alguno.

La Corte, en concordancia con la jurisprudencia del Tribunal Europeo, manifestó en esta sentencia que las garantías diplomáticas no son suficientes en sí mismas para asegurar la protección de una persona contra el riesgo de ser sometida a maltrato, sino que se debe estudiar su efectividad, es decir, que brinden garantías reales en la práctica conforme a las circunstancias respectivas. En consecuencia, se debe examinar la calidad y confiabilidad de las garantías, las cuales se pueden determinar mediante la presencia de algunos factores relevantes, que han sido sistematizados por el Tribunal Europeo en el caso Othman (Abu Qatada) Vs. Reino Unido, No.8139/09, sentencia del 17 de enero de 2012, como los siguientes: 
(i) El hecho de que los términos de las garantías que le hayan sido comunicados o no [a la Corte].

(ii) El carácter, bien sea preciso, bien sea general y vago de las garantías diplomáticas.

(iii) El autor de las garantías y su capacidad, o no, de comprometer al Estado de acogida.

(iv) En los casos en que las garantías diplomáticas han sido ofrecidas por el Gobierno central del Estado de acogida, la probabilidad de que las autoridades locales las cumplan.

(v) El carácter legal o ilegal en el Estado de acogida de los tratamientos respecto de los cuales las garantías diplomáticas han sido dadas.

(vi) El hecho de que procedan, o no, de un Estado contratante.

(vii) La duración y la fuerza de las relaciones bilaterales entre el Estado de envío y el Estado de acogida, incluida la actitud anterior del Estado de acogida frente a garantías similares.

(viii) La posibilidad, o no, de verificar objetivamente el cumplimiento de las garantías ofrecidas mediante mecanismos diplomáticos u otros mecanismos de control, incluida la posibilidad ilimitada de reunirse con los abogados del demandante.

(ix) La existencia, o no, de un verdadero sistema de protección contra la tortura en el Estado de acogida y la voluntad de este Estado de cooperar con los mecanismos internacionales de control (entre las que se encuentran las organizaciones no gubernamentales de defensa de los derechos humanos), de investigar las denuncias de tortura y de sancionar a los autores de tales actos.

(x) El hecho de que el autor haya, o no, sido maltratado en el Estado de acogida.

(xi) El examen o la ausencia de examen por los Tribunales internos del Estado de partida [y/o] del Estado contratante de la fiabilidad de las garantías diplomáticas.

Finalmente, el Tribunal llegó a la conclusión que el señor Wing, al ser 
extraditado, no correría el riesgo de ser sometido a pena de muerte o tratos crueles, inhumanos o degradantes y por ende el Estado de Perú no incurriría en la violación de su obligación de no devolución al extraditarlo, contenido en este caso, en el artículo 13 (párrafo 4) de la Convención interamericana para prevenir y sancionar la tortura.

Por otro lado, conociendo el manejo que la Corte Interamericana le ha dado al principio de no devolución en las anteriores sentencias, es claro que son diversas las herramientas o mecanismos que tienen cierta implicaciónal momento de determinar si se está o no frente a una violación o riesgo contingente de vulnerar el principio de no devolución. De modo que eso le da un contenido aún más especial al mismo, puesto que pone de manifiesto que el derecho de los refugiados y consecuentemente el principio de non-refoulement se ha ido enriqueciendo y no sólo en el ámbito interamericano sino también a nivel europeo, lo cual conlleva a la adopción de posturas y complemento de las mismas entre Tribunales, permitiendo abordar de una mejor forma los casos objetos de análisis.

\section{Conclusiones:}

La violación del principio de no devolución, nos permite vislumbrar el nefasto marco o contexto social que tendríamos en materia de refugiados, si este no hiciere parte del Derecho Internacional, puesto que aún con el conocimiento del marco normativo que rigen el trato a los refugiados y la importancia del deber de aplicación del principio conforme a cada caso, son varias las situaciones que se han presentado en diversos Estados, donde la falta de sujeción a este ha sido evidente.

La invitación que se realiza a la sociedad es a ver en los refugiados, seres humanos que se han visto obligados a abandonar sus países de origen por diversas situaciones preocupantes, que arriban en fundados temores de peligro para su vida misma e incluso la de sus familiares, por lo cual requieren de la mayor solidaridad posible que les permita superar su situación. Consecuentemente, la invitación a los Estados es a 
velar siempre por la aplicación del principio de no devolución, que, como vimos anteriormente, es la piedra angular del derecho de los refugiados, analizando cada caso específicamente para adoptar la decisión correcta en cuestiones de permanencia o no de los solicitantes de asilo; teniendo presente que la devolución de los refugiados, les podría generar responsabilidad en caso de que se realice sin motivación acertada y se atente contra la vida e integridad de estos, aun habiéndolos devuelto o no desde la soberanía de sus territorios.

\section{Referencias bibliográficas:}

Alto Comisionado de las Naciones Unidas para los Refugiados. (1993). Nota sobre Protección Internacional, A/AC.96/815.

Alto Comisionado de las Naciones Unidas para los Refugiados. (2001). Guía sobre el derecho internacional de los refugiados.

Alto Comisionado de las Naciones Unidas para los Refugiados. (2007). Opinión Consultiva sobre la aplicación extraterritorial de las obligaciones de no devolución en virtud de la Convención sobre el Estatuto de los Refugiados de 1951 y su Protocolo de 1967.

Alto Comisionado de las Naciones Unidas para los Refugiados. (2007). La Convención de 1951 sobre el Estatuto de los Refugiados. Preguntas y respuestas.

Alto Comisionado de las Naciones Unidas para los Refugiados. (2008). Nota de Orientación sobre la Extradición y la Protección Internacional de los Refugiados.

Alto Comisionado de las Naciones Unidas para los Refugiados. (2010). Protección de los refugiados en el derecho internacional; consultas globales de ACNUR sobre protección internacional. Editorial Icaria. Barcelona, España. 
Alto Comisionado de las Naciones Unidas para los Refugiados. (2011). Manual y directrices sobre procedimientos y criterios para determinar la condición de refugiado.

Alto Comisionado de las Naciones Unidas para los Refugiados. (2017). Ficha técnica sobre el derecho a buscar y recibir asilo.

Alto Comisionado de las Naciones Unidas para los Refugiados. (2018). Tercera ficha técnica sobre el derecho a la no devolución y no expulsión.

Alto Comisionado de las Naciones Unidas para los Refugiados. (s.f). Asilo político y solicitud de asilo: 5 claves para entenderlo. Recuperado de https://eacnur.org/es/asilo-politico-y-solicitud-de-asilo-5-clavespara-entenderlo

Alto Comisionado de las Naciones Unidas para los Refugiados. (s.f). Asilo: definición y características básicas. Recuperado de https:// eacnur.org/blog/asilo-definicion-caracteristicas-basicas/

Cañardo H. (2013). La extradición, el delito político, y el asilo extraterritorial a la luz de los principios del derecho internacional público. Revista de Derecho, (8), págs.81-115. Recuperado de: https:// dialnet.unirioja.es/servlet/articulo?codigo=6119779

Comité Ejecutivo del Alto Comisionado de las Naciones Unidas. (1980). Conclusión sobre Problemas de extradición que afectan a los refugiados, No. 17 (XXXI).

Comité Ejecutivo del Alto Comisionado de las Naciones Unidas. (1991). Conclusionessobrela proteccióninternacional de los refugiados aprobadas por el Comité Ejecutivo, No. 65 (XLII) conclusiones generales.

Corte Interamericana de Derechos Humanos. Caso Nadege Dorzema y otros vs. República Dominicana. Fondo, Reparaciones y 
Costas. Sentencia de 24 de octubre de 2012. Serie C 251

Corte Interamericana de Derechos Humanos. Caso Familia Pacheco Tineo VS Estado Plurinacional de Bolivia. Excepciones Preliminares, fondo, reparaciones y costas. Sentencia de 25 de noviembre de 2013.

Corte Interamericana de Derechos Humanos. (19 de agosto de 2014). Opinión Consultiva OC 21.

Corte Interamericana de Derechos Humanos. Caso Wong Ho Wing vs. Perú. Excepción Preliminar, Fondo, Reparaciones y Costas. Sentencia de 30 de junio de 2015. Serie C 297.

Conferencia especializada interamericana sobre derechos humanos. (1969). Convención Americana sobre Derechos Humanos (Pacto de San José). San José, Costa Rica.

Comité Ejecutivo del ACNUR. (1980). Conclusión No. 17 (XXXI) Problemas de extradición que afectan a los refugiados.

Coloquio Sobre la Protección Internacional de los Refugiados en América Central, México y Panamá: Problemas Jurídicos y Humanitarios. (1984). Declaración de Cartagena sobre Refugiados de 1984.

Garretón M. (1995). "Principio de no devolución”. Fuerza normativa, alcances, aplicación en los países no partes en la Convención. Memoria Coloquio Internacional, 10 años de la Declaración de Cartagena sobre Refugiados, Primera edición IIDH-ACNUR., pág. 211-232.

Instituto de Políticas Públicas en Derechos Humanos del Mercosur \& Organización Internacional para las Migraciones. (s.f). Derechos humanos de personas migrantes, manual regional.

León A. (2005). "Teorías y conceptos asociados al estudio de las migraciones internacionales" Revista Trabajo Social, (7), 
págs. 59-76. Recuperado de: https://dialnet.unirioja.es/servlet/ articulo?codigo $=4391739$

Organización de los Estados Americanos. (1969). Convención Americana sobre Derechos Humanos (Pacto de San José).

Protocolo sobre el Estatuto de los Refugiados. (1967).

Rubio P. (1999). "El concepto de refugiado en la Convención sobre el Estatuto de los Refugiados de 1951: tratamiento normativo y realidad". Revista Agenda Internacional, vol. 3, (12), págs. 137-148.

Recuperado de:

https://dialnet.unirioja.es/buscar/documentos?querysDismax. DOCUMENTAL_TODO=El+concepto+de+Refugiado+en+la+conven ci\%C3\%B3n+sobre+el+estatuto+de+los+refugiados+de+1951\%3A+ tratamiento+normativo+y+realidad

Revista Migraciones Forzadas. (Febrero de 2017). Los riesgos tras la deportación y su seguimiento. Recuperado de:

https://www.fmreview.org/sites/fmr/files/FMRdownloads/es/ reasentamiento/tras-deportacion.pdf 
Principio de no devolución y su aplicación extraterritorial: pilar fundamental en el marco del derecho de los refugiados 